\section{“For science and Russia"}

\section{Moscow}

THE Russian (as distinct from the Soviet) Academy of Sciences held its first general meeting last month, to confirm the election of over 400 members and alternate members. But the future of the institution is still uncertain: there is as yet no assured budget, while the academy has still to show itself a worthy counterpoise to the "big academy, the Academy of Sciences of the USSR."

The new academy has come into being, according to president Dmitry Mineev, "in the interests of science and Russia". Mineev, head of the mineralogy and geophysics department at the Moscow Institute of Geology and Prospecting, is the author of 300 scientific papers and the discoverer of eight phosphate and rare metal deposits on the Kola peninsula. Traditionally, Russia has differed from most other republics in not having an academy of its own; it was formerly held that the big academy covered its functions, although only 10 per cent of its full members are from Russia.

The new academy (abbreviated to RAEN) has had a hard birth. While RAEN's founders were engaged in heated debate over the principles of its constitution, the presidium of the big academy seized the opportunity by resolving to form its own Rusian Academy and by appointing Nobel prizewinner physicist Alexander Prokhorov as its president. But the plan to form an academy "from above" was not to the liking of many working scientists. Prokhorov refused to assume the post and that project remains in limbo.

RAEN was formed by a group of universities and colleges, research centres and Soviet academy institutes. At its first conference last autumn, 140 full and alternate members were elected, which list has now been enlarged. The vice-presidents elected last month are biologist Nikolai Vorontsov, chairman of the USSR Environmental Protection Committee, physicist Sergei Kapitsa, president of the Soviet Physical Society and laboratory chief of the Vavilov Institute of Physical Problems, and geologist Oleg Kuznetsov, director of the All-Union Research Institute of Geological and Geophysical information Systems.

Unlike the big academy, RAEN will not limit its membership, so that it will not be necessary for deserving candidates to wait for a vacancy. Far from being paid for their fellowship, RAEN members pay dues - a symbolic 25 roubles a year. The academy has no subordinate agencies that might bring it funds, but intends to form and finance ad hoc research groups to carry out studies.

The budget problem seems likely to persist. The 600,000 roubles contributed by its founders is just a drop in the bucket. The founders intended the academy as a stateowned organization financed by the government of the Russian Federation. But the

\section{Turin} rels) of heavy Iranian crude oil.
Russian authorities see it as a public organization, which does not exclude budget financing of the particular themes and programmes commissioned by the Russian government, but which explains Mineev's calls for a search for other sources of finance.

RAEN has six sections: physics; chemistry; the Earth sciences; mathematics, informatics and cybernetics; biology and medicine; and Russian encyclopaedia. The last refers to a joint project with the organization known as Resurrection to compile and publish an ample encyclopaedia series dedicated to the history of the science and culture of people living on Russian territory. Among the planned volumes are encyclopaedias in
Russian science, the Russian army and the Russian fleet, Russian aristocracy, The Churches of Russia and a children's encylopaedia. The academy's other projects include plans to publish several scientific and popular magazines.

Last month's general assembly also elected its first honorary members: Alexander Solzhenitsyn, Iosif Brodsky, Mstislav Rostropovich and Yehudi Menuhin, as well as 18 Nobel prizewinners who are either of Russian origin or the offspring of former subjects of the Russian empire - Wassily Leontief (Harvard), Ilya Prigogine (Brussels), Andre Lwoff (Institut Pasteur), Bernard Katz (London), Milton Friedman (Chicago) and so on. Raen hopes these contacts will lead to collaboration within the Russian diaspora.

Yurl Kanin

\title{
Riviera under threat
}

THE Italian and French authorities have declared a state of emergency, after the western Mediterranean - and with it the economically important tourist beaches of the Riviera - was threatened by the spillage of up to 147,000 tonnes (about 1 million bar-

The Cypriot-registered tanker Haven is now lying in some 70 metres of water a few kilometres off the coast at Genoa, with up to 100,000 tonnes of its cargo still on board. The ship sank at the weekend, after being crippled by a series of explosions. Italian en-

\section{IMAGE UNAVAILABLE FOR COPYRIGHT REASONS}

The view across Genoa harbour, Italy, last Saturday. (AP)

vironment minister Giorgio Ruffolo, in Turin on Monday to open a three-day meeting on Oceans, Climate and Man, organized by the Foundation San Paolo, said that underwater surveys were already underway to see if this oil can be salvaged, to prevent further spillage.

Pumping oil to a tanker at the surface will be a difficult operation, requiring the careful replacement of oil with sea water, to prevent the Haven shifting and breaking up, but is feasible.

Italian efforts to contain the spill have so far won general approval. Domitilla Senni, from Greenpeace's office in Rome, applauded the decision to tow the tanker several kilometers nearer the shore, before allowing it to sink. The sea floor slopes sharply south of Genoa, making any slavage attempt further offshore difficult, if not impossible.

Ruffolo had been under pressure to move the vessel away from the Italian coast, but said that this would have been "irresponsible" - creating the danger of a more widespread, longer term incident.

Most of the spilled oil has burned, but a large slick was on Monday being held by contaiment booms over the sunken tanker, and oil released at the original explosion was reported to be coming ashore at Alassio, $100 \mathrm{~km}$ to the west. The extent of the ecological and economic damage will depend on the weather over the coming weeks. As Nature went to press, conditions were calm, but strong winds would badly hamper the effort to contain and collect the oil.

Claude Millot, from the CNRS Centre d'Oceanologie de Marseille, France, says that sea currents and prevailing winds will tend to carry any oil that escapes westwards along the Italian and French coasts.

Ruffolo said that he will be pressing for tighter European Communities (EC) controls over the transport of oil in the Mediterranean at a meeting of EC environment ministers on 30 June. But the fundamental problem, he said, is the heavy volume of oil traffic in and out of Italy's 30 oil terminals. Italy now relies on oil for almost 60 per cent of its energy needs.

Peter Aldhous 